\title{
A survey study of women's responses to information about overdiagnosis in breast cancer screening in Britain
}

\author{
$\mathrm{J} \mathrm{Waller}^{\star, 1}, \mathrm{KL}$ Whitaker $^{1}, \mathrm{~K}$ Winstanley $^{1}, \mathrm{E} \mathrm{Power}^{2}$ and J Wardle ${ }^{1}$ \\ ${ }^{1}$ Health Behaviour Research Centre, Department of Epidemiology \& Public Health, UCL, Gower Street, London WC1E 6BT, UK \\ and ${ }^{2}$ Cancer Research UK, Angel Building, 407 St John Street, London EC1V 4AD, UK
}

Background: There is concern about public understanding of overdiagnosis in breast cancer screening, and uncertainty about the likely impact on screening participation.

Methods: In a population-based survey of 2272 women, we assessed understanding of overdiagnosis and screening intentions before and after exposure to an explanation of overdiagnosis, and one of the three information formats providing an estimate of the rate of overdiagnosis based on the findings of the UK Independent Review.

Results: Subjective and objective comprehension of overdiagnosis was moderate across information formats (64\% and 57\%, respectively). Following overdiagnosis information, $7 \%$ of women showed a decrease in screening intention, with a stronger effect among women below screening age ( $<47$ years), and receiving the estimate of the rate of overdiagnosis in a simple ratio format (one life saved to three overdiagnoses).

Conclusions: Brief written information on overdiagnosis was incompletely understood, but reduced breast screening intentions in a proportion of women, regardless of comprehension. Subjective comprehension was lower among women who had not yet reached screening age but the deterrent effect was higher.

Opinions on the efficacy of mammography screening for breast cancer are divided in the scientific community (Duffy et al, 2010; Gotzsche and Jorgensen, 2011). The lack of consensus among experts, together with intrinsic difficulties in accurately estimating rates of overdiagnosis, makes communicating with the public about the harms and benefits of breast screening challenging. A recent independent review in the UK concluded that mammography screening is effective, but estimated that, for every life saved by the NHS breast screening programme, approximately three women are diagnosed and treated for a cancer that never would have harmed them (Independent UK Panel on Breast Screening, 2012), though this estimate is far from certain. The review recommended that the NHS information materials should include clear information on overdiagnosis, and they now include this information in three formats (NHS, 2013).
Despite a rigorous development process (Hawkes, 2012; Informed Choice about Cancer Screening, 2014), little is known about the public's understanding of overdiagnosis or the likely impact of overdiagnosis information on women's choices about screening participation. Recent qualitative studies found that information on overdiagnosis was difficult for screening-eligible women to understand and was often surprising (Hersch et al, 2013; Waller et al, 2013), but did not appear to have much impact on screening intentions.

The first aim of this study was to assess change in screening intention in response to overdiagnosis information, and to test the hypothesis that intentions would be reduced more among women who had not yet been invited for screening than those already eligible, whose attitudes may be resistant to change.

*Correspondence: Dr J Waller; E-mail: j.waller@ucl.ac.uk

Received 21 May 2014; revised 22 July 2014; accepted 7 August 2014; published online 28 August 2014 
Table 1. Baseline characteristics of the sample by screening eligibility ( $n$ and column \%)

\begin{tabular}{|c|c|c|c|}
\hline & $\begin{array}{l}\text { Not yet eligible for } \\
\text { screening }(n=1318)\end{array}$ & $\begin{array}{l}\text { Eligible for screening } \\
\qquad(n=954)\end{array}$ & $P$ for difference \\
\hline Age in years (mean; standard deviation; range) & $35.3(6.3) 25-46$ & $62.1(5.2) 53-70$ & NA \\
\hline \multicolumn{4}{|l|}{ Marital status } \\
\hline $\begin{array}{l}\text { Married/living as married } \\
\text { Single } \\
\text { Separated/divorced/widowed }\end{array}$ & $\begin{array}{c}848(64.3) \\
352(26.7) \\
118(9.0)\end{array}$ & $\begin{array}{l}585(61.3) \\
80(8.4) \\
289(30.3)\end{array}$ & $\begin{array}{c}\chi^{2}(2)=239.2 \\
P<0.0001\end{array}$ \\
\hline \multicolumn{4}{|l|}{ Socioeconomic status ${ }^{a}$} \\
\hline $\begin{array}{l}0 \text { (most deprived) } \\
1 \\
2 \\
3 \text { (most affluent) }\end{array}$ & $\begin{array}{l}220(16.9) \\
432(33.3) \\
379(29.2) \\
268(20.6)\end{array}$ & $\begin{array}{l}145(15.6) \\
359(38.6) \\
287(30.8) \\
140(15.0)\end{array}$ & $\begin{array}{c}\chi^{2}(3)=14.7 \\
P=0.002\end{array}$ \\
\hline \multicolumn{4}{|l|}{ Breast screening history } \\
\hline $\begin{array}{l}\text { Never screened } \\
6 \text { or more years ago } \\
3-5 \text { years ago } \\
\text { Less than } 3 \text { years ago }\end{array}$ & NA & $\begin{array}{c}82(8.7) \\
41(4.4) \\
155(16.5) \\
662(70.4)\end{array}$ & NA \\
\hline \multicolumn{4}{|l|}{ Breast screening intention (pre-information) } \\
\hline $\begin{array}{l}\text { Probably/definitely yes } \\
\text { Not sure } \\
\text { Probably/definitely not }\end{array}$ & $\begin{array}{c}1187(90.1) \\
78(5.9) \\
53(4.0)\end{array}$ & $\begin{array}{c}872(91.4) \\
24(2.5) \\
58(6.1)\end{array}$ & $\begin{array}{c}\chi^{2}(2)=19.2 \\
P<0.0001\end{array}$ \\
\hline \multicolumn{4}{|l|}{ Previous awareness of overdiagnosis } \\
\hline $\begin{array}{l}\text { Aware } \\
\text { Unaware/don't know }\end{array}$ & $\begin{array}{l}592(44.9) \\
726(55.1)\end{array}$ & $\begin{array}{l}608(63.7) \\
346(36.3)\end{array}$ & $\begin{array}{l}\chi^{2}(1)=78.6 \\
P<0.0001\end{array}$ \\
\hline
\end{tabular}

The second aim was to compare the three formats of overdiagnosis information included in the NHS information materials. We hypothesised that the simple ratio format (lives saved: overdiagnoses) would be easier to understand - and therefore have more impact on screening intentions - than information involving actual (large) numbers of lives saved or women overdiagnosed (Trevena et al, 2013).

We addressed these aims using an experimental design in a large, population-based sample. Participants were randomised to one of the three formats of overdiagnosis information that are in the current NHS leaflet. Comprehension was assessed after exposure. Intention to attend was assessed before and after information exposure. Given the particular interest in the extent to which overdiagnosis information would reduce screening participation, our main outcome of interest was decreased intention.

\section{MATERIALS AND METHODS}

The survey was carried out as part of TNS-International's omnibus survey in July 2013 using stratified random location sampling and home-based computer-assisted personal interviewing. Data were analysed from 2272 women aged 25-46 (below screening age) and 53-70 years (screening eligible), in England, Scotland or Wales (see 'Supplementary File 1' for details of participant flow).

The main outcome measure was intention to participate in future breast screening (see 'Supplementary File 2' for details of measures and coding). This was asked before and after exposure to overdiagnosis information. Change in intention was coded as 'decrease' vs 'no decrease'.
Before information exposure, we assessed previous awareness of overdiagnosis. Subjective comprehension of the overdiagnosis information was assessed using items adapted from Woloshin et al (2005), and objective comprehension by asking whether attending screening increased or decreased the likelihood of a breast cancer diagnosis (Hersch et al, 2013). Previous breast screening participation, age, marital status and socioeconomic status (based on the sum of responses to questions on occupational group, education, and car ownership) were also assessed.

Participants received a brief explanation of the concept of overdiagnosis (for details, see 'Supplementary File 3') and were randomised to one of three information conditions: Version 1 in which the rate of overdiagnosis was framed as a ratio (one life saved to three overdiagnoses), Version 2, which gave the total number of overdiagnoses compared with lives saved in the UK (4000 and 1300, respectively), or Version 3, which gave the numbers of overdiagnoses and lives saved for every 200 women screened for 20 years ( 3 and 1). All information was taken from the new breast screening leaflet.

Analyses were carried out using PASW Statistics 20 (IBM Corp, 2011).

\section{RESULTS}

Baseline measures. Characteristics of the sample $(n=2272)$ divided into the age-eligible range for screening $(n=954)$ and not yet eligible for screening $(n=1318)$ are shown in Table 1 . At baseline, screening intention was high (91\%, 2059/2272, expressed a positive intention), and slightly higher in the age-eligible group. 
Table 2. Differences in follow-up measures by screening eligibility and information version ( $n$ and column \%)

Differences by screening eligibility

Differences by information version

\begin{tabular}{|c|c|c|c|c|c|c|c|}
\hline $\begin{array}{c}\text { Whole } \\
\text { sample } \\
(n=2272)\end{array}$ & $\begin{array}{c}\text { Not yet } \\
\text { eligible } \\
(n=1318)\end{array}$ & $\begin{array}{l}\text { Screening } \\
\text { eligible } \\
(n=954)\end{array}$ & Difference & $\begin{array}{c}\text { Version } 1 \\
(3: 1 \\
\text { ratio }) \\
(n=758)\end{array}$ & $\begin{array}{c}\text { Version } 2 \\
\text { (total } \\
\text { numbers) } \\
(n=736)\end{array}$ & $\begin{array}{l}\text { Version } 3 \\
\text { (per 200 } \\
\text { women) } \\
(n=778)\end{array}$ & Difference \\
\hline
\end{tabular}

Breast screening intention (post-info)

\begin{tabular}{|c|c|c|c|c|c|c|c|c|}
\hline $\begin{array}{l}\text { Probably/definitely yes } \\
\text { Not sure } \\
\text { Probably/definitely not }\end{array}$ & $\begin{array}{c}2041(90.2) \\
118(5.2) \\
103(4.6)\end{array}$ & $\begin{array}{c}1169(89.0) \\
95(7.2) \\
50(3.8)\end{array}$ & $\begin{array}{c}872(92.0) \\
23(2.4) \\
53(5.6)\end{array}$ & $\begin{array}{c}\chi^{2}(2)=28.8 \\
P<0.0001\end{array}$ & $\begin{aligned} 683 & (90.5) \\
37 & (4.9) \\
35 & (4.6)\end{aligned}$ & $\begin{aligned} 669 & (91.4) \\
37 & (5.1) \\
26 & (3.6)\end{aligned}$ & $\begin{array}{c}689(88.9) \\
44(5.7) \\
42(5.4)\end{array}$ & $\begin{array}{c}\chi^{2}(4)=3.7 \\
P=0.45\end{array}$ \\
\hline Missing & 10 & & & & & & & \\
\hline
\end{tabular}

Change in intention (pre- to post-info)

\begin{tabular}{|l|c|c|c|c|c|c|c|c|}
\hline $\begin{array}{l}\text { No change/Increase in } \\
\text { intention } \\
\text { Decrease in intention }\end{array}$ & $2112(93.4)$ & $1207(91.9)$ & $905(95.5)$ & $\chi^{2}(1)=11.6$, & $689(91.3)$ & $695(94.9)$ & $728(93.9)$ & $\chi^{2}(2)=8.8$, \\
\hline Missing & $150(6.6)$ & $107(8.1)$ & $43(4.5)$ & $P=0.001$ & $66(8.7)$ & $37(5.1)$ & $47(6.1)$ & $P=0.01$ \\
\hline
\end{tabular}

Objective understanding of overdiagnosis ${ }^{a}$

\begin{tabular}{|c|c|c|c|c|c|c|c|c|}
\hline $\begin{array}{l}\text { Correct } \\
\text { Incorrect/don't know }\end{array}$ & $\begin{array}{r}1283(56.7) \\
981(43.3)\end{array}$ & $\begin{array}{l}784(59.7) \\
529(40.3)\end{array}$ & $\begin{array}{l}499(52.5) \\
452(47.5)\end{array}$ & $\begin{array}{c}\chi^{2}(1)=11.8 \\
P=0.001\end{array}$ & $\begin{array}{l}436(57.8) \\
318(42.2)\end{array}$ & $\begin{array}{l}411(55.9) \\
324(44.1)\end{array}$ & $\begin{array}{l}436(56.3) \\
339(43.7)\end{array}$ & $\begin{array}{c}\chi^{2}(2)=0.6 \\
P=0.73\end{array}$ \\
\hline Missing & 8 & & & & & & & \\
\hline
\end{tabular}

Subjective understanding of overdiagnosis ${ }^{\mathrm{b}}$

\begin{tabular}{|c|c|c|c|c|c|c|c|c|}
\hline $\begin{array}{l}\text { Any uncertainty } \\
\text { No uncertainty }\end{array}$ & $\begin{array}{r}802(35.6) \\
1449(64.4)\end{array}$ & $\begin{array}{l}497(38.0) \\
812(62.0)\end{array}$ & $\begin{array}{l}305(32.4) \\
637(67.6)\end{array}$ & $\begin{array}{r}\chi^{2}(1)=7.5 \\
P=0.006\end{array}$ & $\begin{array}{l}256(34.3) \\
490(65.7)\end{array}$ & $\begin{array}{l}266(36.2) \\
468(63.8)\end{array}$ & $\begin{array}{l}280(36.3) \\
491(63.7)\end{array}$ & $\begin{array}{c}\chi^{2}(2)=0.8 \\
P=0.66\end{array}$ \\
\hline Missing & 21 & & & & & & & \\
\hline $\begin{array}{l}\text { Significant group } \\
\mathbf{a}_{\text {Response to the }} \\
\text { mammograms (inc } \\
\mathbf{b}_{\text {Derived from thre }} \\
\text { wording and codin }\end{array}$ & $\begin{array}{l}\text { shown in bold } \\
\text { do you think is } \\
\text { sing ease of un }\end{array}$ & $\begin{array}{l}\text { les sizes vary s } \\
\text { likely to be di } \\
\text { ding, confider }\end{array}$ & $\begin{array}{l}\text { between anal } \\
\text { ed with breast } \\
\text { having made s }\end{array}$ & $\begin{array}{l}\text { lue to missing } \\
\text { r? Women wh } \\
\text { of the informat }\end{array}$ & $\begin{array}{l}\text { ve screening } \\
\text { and knowing }\end{array}$ & $\begin{array}{l}\text { mograms (cor } \\
\text { o interpret th }\end{array}$ & mation; see Sur & mentary File 2 for \\
\hline
\end{tabular}

Around half were already aware of overdiagnosis (53\%, 1200/ 2272); slightly more in the age-eligible group.

Post-information measures. Subjective comprehension of overdiagnosis information was expressed by about two-thirds of women, with $64 \%$ showing no uncertainty on any of the subjective measures (Table 2). Objective understanding was slightly lower, with $57 \%$ correct. Younger women's objective understanding was better than older women's ( $60 \%$ vs $53 \%$ correct, respectively), but they were less subjectively certain (62\% vs $68 \%$, respectively). Subjective and objective comprehension were modestly correlated in the whole group $(r=0.14, P=0.01)$ and both age groups (younger: $r=0.14, P=0.01$; older: $r=0.16 P=0.01$ ). There were no differences in objective or subjective comprehension by version (see Table 2).

Screening intentions remained high after information exposure; $90 \%$ of respondents said they would 'probably' or 'definitely' attend (Table 2). Among the 2262 respondents who answered the intention question at both time points, $89 \%$ had no change in intention, $4 \%$ increased their intention and $7 \%$ decreased their intention. As hypothesised, younger women were more likely than older women to show decreased intentions to participate ( $8 \%$ vs $5 \%$, respectively; Table 2).

Consistent with our second hypothesis, significantly more respondents exposed to Version 1 (ratio information) decreased their intention (9\%), compared with Version 2 (5\%) or Version 3 (6\%) (Table 2).
We used logistic regression analyses to examine predictors of decreased screening intention (Table 3) controlling for marital status and socioeconomic status. Decreased intention was more likely in respondents not yet eligible for screening $(\mathrm{OR}=1.96$; $95 \%$ CI: 1.33-2.89), exposed to Version 1 vs the other formats $(\mathrm{OR}=1.50 ; 95 \% \mathrm{CI}: 1.02-2.22)$, with no prior awareness of overdiagnosis $(\mathrm{OR}=1.48$; 95\% CI: 1.05-2.08), and who expressed subjective uncertainty about comprehension $(\mathrm{OR}=1.47 ; 95 \% \mathrm{CI}$ : 1.04-2.06). To test whether prior awareness or comprehension mediated the age or version effects, we used a multivariate model. Screening eligibility, version and subjective uncertainty remained significantly associated with decreased intention, with little change in the odds ratios. Previous awareness of overdiagnosis became non-significant, indicating it was likely to be a marker of screening eligibility.

\section{DISCUSSION}

In this population-based sample of women, prior awareness of overdiagnosis in breast screening was moderate (53\%), and significantly lower (45\%) in women not yet age-eligible for the national breast screening programme. After exposure to any of the three formats of overdiagnosis information used in the NHS information leaflet, just over a third of women (36\%) expressed some uncertainty about their ability to interpret the information, and almost half (43\%) failed to understand that screening increases 
Table 3. Odds of decreased screening intention

\begin{tabular}{|c|c|c|c|}
\hline & $\begin{array}{l}\text { n (row \%) decreasing } \\
\text { intention }\end{array}$ & $\begin{array}{c}\text { Adjusted odds ratios }^{a} \\
\text { (Cl: 95\%) } \\
n=2213-2223\end{array}$ & $\begin{array}{c}\text { Fully adjusted model } \\
\text { Odds ratio (Cl: } 95 \%) \\
\qquad n=2207\end{array}$ \\
\hline \multicolumn{4}{|l|}{ Screening eligibility group } \\
\hline $\begin{array}{l}\text { Screening eligible (ref) } \\
\text { Not yet eligible }\end{array}$ & $\begin{array}{r}43(4.5) \\
107(8.1)\end{array}$ & $\begin{array}{c}1.00 \\
1.96(1.33-2.89)\end{array}$ & $\begin{array}{c}1.00 \\
1.84(1.24-2.74)\end{array}$ \\
\hline \multicolumn{4}{|l|}{ Information version } \\
\hline $\begin{array}{l}\text { Version } 3 \text { (per } 200 \text { women) (ref) } \\
\text { Version } 1 \text { ( } 3: 1 \text { ratio) } \\
\text { Version } 2 \text { (total numbers) }\end{array}$ & $\begin{array}{l}47(6.1) \\
66(8.7) \\
37(5.1)\end{array}$ & $\begin{array}{c}1.00 \\
1.50(1.02-2.22) \\
0.81(0.52-1.26)\end{array}$ & $\begin{array}{c}1.00 \\
1.62(1.09-2.40) \\
0.83(0.53-1.30)\end{array}$ \\
\hline \multicolumn{4}{|l|}{ Previous awareness of OD } \\
\hline $\begin{array}{l}\text { Aware } \\
\text { Unaware/don't know }\end{array}$ & $\begin{array}{l}66(5.5) \\
84(7.9)\end{array}$ & $\begin{array}{c}1.00 \\
1.48(1.05-2.08)\end{array}$ & $\begin{array}{c}1.00 \\
1.31(0.92-1.86)\end{array}$ \\
\hline \multicolumn{4}{|c|}{ Objective understanding of OD } \\
\hline $\begin{array}{l}\text { Correct (ref) } \\
\text { Incorrect/don't know }\end{array}$ & $\begin{array}{l}86(6.7) \\
63(6.5)\end{array}$ & $\begin{array}{c}1.00 \\
0.94(0.66-1.32)\end{array}$ & $\begin{array}{c}1.00 \\
0.93(0.65-1.32)\end{array}$ \\
\hline \multicolumn{4}{|c|}{ Subjective understanding of overdiagnosis information } \\
\hline $\begin{array}{l}\text { No uncertainty (ref) } \\
\text { Any uncertainty }\end{array}$ & $\begin{array}{l}83(5.7) \\
66(8.3)\end{array}$ & $\begin{array}{c}1.00 \\
1.47(1.04-2.06)\end{array}$ & $\begin{array}{c}1.00 \\
1.43(1.01-2.02)\end{array}$ \\
\hline \multicolumn{4}{|c|}{$\begin{array}{l}\text { Abbreviation:OD = overdiagnosis. } \\
\text { a Odds ratios are adjusted for marital status and SES. Sample sizes vary owing to missing data. } \\
\text { b }_{\text {Model includes all the variables in the table and adjusts for marital status and SES. }}\end{array}$} \\
\hline
\end{tabular}

the risk of a breast cancer diagnosis; poorer understanding of overdiagnosis than has been found following more detailed explanations (Hersch et al, 2013). This suggests that, even leaving aside the fact that that rate of overdiagnosis is a highly contested issue, the concept itself is difficult to understand. Brief information, of the sort sent to women in the UK with their screening appointment, may not be enough to facilitate informed choice.

Although intentions to attend screening remained high after overdiagnosis information, $5 \%$ of age-eligible women showed decreased intentions to participate in screening; rising to $8 \%$ among women not yet eligible for screening. This provides support for our hypothesis that overdiagnosis information would have more impact on women for whom a screening decision was novel, whereas those already in the screening programme may have stable beliefs and intentions.

We found small differences in intention change between different versions of the numerical information. Expressing the information as a ratio of lives saved to overdiagnoses $(1: 3)$ was associated with a greater decrease in intention than the other information formats. This suggested a better understanding of information presented using small numbers, but in the analyses, the effect of version was not explained by comprehension. The perceived likelihood of overdiagnosis rather than the phenomenon itself maybe more off-putting in the ratio format.

One limitation of the study is that women were provided with little time to process the information, and thus our findings demonstrate only its immediate impact. The outcome was intention rather than actual screening uptake, which was inevitable as we were interested in women outside the eligible age range, but future research should assess the impact on actual screening uptake. We did not have information on survey nonresponders so cannot rule out the possibility that our sample differed systematically from the wider population, although by using an omnibus survey, we minimised the chance that participation would be biased by health-related beliefs. Finally, we used the term 'overdiagnosis' rather than 'overtreatment', which has been found to be preferred by some women (Hersch et al, 2013) and provided only brief information that did not give a nuanced account of the range of outcomes that might be experienced following overdiagnosis. This may have had an impact on our findings.

This study suggests that brief, written information on overdiagnosis is unlikely to have a major impact on participation in breast screening, but may be off-putting to women not yet eligible for screening, particularly when they see the $1: 3$ ratio of lives saved to overdiagnoses. If $8 \%$ of women invited for screening for the first time decided not to attend, this would represent a significant drop in screening coverage in the long term. More research is needed to explore the impact of presenting women with personalised information or with a range of estimates of the harms and benefits of screening, as has been described in a recent US paper (Welch and Passow, 2014). It will also be important to see whether international differences in attitudes exist; and whether attitudes change over time, as women are exposed to more information about the limitations of screening.

Women in the general population in Britain appear to be less concerned by the prospect of overdiagnosis than some clinicians; although the simplest information format resulted in a small reduction in intentions to participate, especially among women who had not yet reached screening age. The relatively poor comprehension combined with little impact on intentions suggests that brief written materials may not achieve a full appreciation of the balance of harms and benefits of breast screening, or counteract the public's very positive attitudes towards cancer screening in general (Schwartz et al, 2004). However, the limited impact on intentions could also be interpreted in the context of the 'better safe than sorry' philosophy that has been observed in qualitative research. 


\section{ACKNOWLEDGEMENTS}

This work was supported by Cancer Research UK.

\section{CONFLICT OF INTEREST}

The authors declare no conflict of interest.

\section{REFERENCES}

Duffy SW, Tabar L, Olsen AH (2010) Absolute numbers of lives saved and overdiagnosis in breast cancer screening, from a randomized trial and from the Breast Screening Programme in England. J Med Screen 17(2): 106.

Gotzsche PC, Jorgensen KJ (2011) The breast screening programme and misinforming the public. J R Soc Med 104(9): 361-369.

Hawkes N (2012) Women "jurors" are asked how to present risk-benefit ratio of breast cancer screening. BMJ 345: e7886.

Hersch J, Jansen J, Barratt A, Irwig L, Houssami N, Howard K, Dhillon H, McCaffery K (2013) Women's views on overdiagnosis in breast cancer screening: a qualitative study. BMJ 346: f158.

IBM Corp (2011) Released 2011. IBM SPSS Statistics for Windows, Version 20.0. IBM Corp: Armonk, NY, USA.
Independent UK Panel on Breast Screening (2012) The benefits and harms of breast cancer screening: an independent review. Lancet 380(9855): 1778-1786. Informed Choice about Cancer Screening. Retrieved 21 May (2014) from http://www.informedchoiceaboutcancerscreening.org.

NHS (2013) NHS breast screening: helping you decide. Retrieved 21 May 2014 from http://www.cancerscreening.nhs.uk/breastscreen/publications/ nhsbsp.pdf.

Schwartz LM, Woloshin S, Fowler FJ, Welch HG (2004) Enthusiasm for cancer screening in the United States. JAMA 291(1): 71-78.

Trevena LJ, Zikmund-Fisher BJ, Edwards A, Gaissmaier W, Galesic M, Han PK, King J, Lawson ML, Linder SK, Lipkus I, Ozanne E, Peters E, Timmermans D, Woloshin S (2013) Presenting quantitative information about decision outcomes: a risk communication primer for patient decision aid developers. BMC Med Inform Decis Mak 13(Suppl 2): S7.

Waller J, Douglas E, Whitaker KL, Wardle J (2013) Women's responses to information about overdiagnosis in the UK breast cancer screening programme: a qualitative study. BMJ Open 3(4): doi:bmjopen-2013-002703.

Welch HG, Passow HJ (2014) Quantifying the benefits and harms of screening mammography. JAMA Intern Med 174(3): 448-454.

Woloshin S, Schwartz LM, Welch HG (2005) Patients and medical statistics Interest, confidence, and ability. J Gen Intern Med 20(11): 996-1000.

(c) (1) (2) This work is licensed under the Creative Commons BY Ac SA Attribution-NonCommercial-Share Alike 3.0 Unported License. To view a copy of this license, visit http://creativecommons. org/licenses/by-nc-sa/3.0/

Supplementary Information accompanies this paper on British Journal of Cancer website (http://www.nature.com/bjc) 